\title{
ATRAP Expression in Brown Adipose Tissue Does Not Influence the Development of Diet-Induced Metabolic Disorders in Mice
}

\author{
Kohji Ohki ${ }^{1, \dagger}{ }^{,}$Hiromichi Wakui ${ }^{1, *,+}$, Kengo Azushima ${ }^{1,2, *,+}$, Kazushi Uneda ${ }^{1}$, Sona Haku ${ }^{1}$, \\ Ryu Kobayashi ${ }^{1}$, Kotaro Haruhara ${ }^{1}$, Sho Kinguchi ${ }^{1}$, Miyuki Matsuda ${ }^{1}$, Masato Ohsawa ${ }^{1}$, \\ Akinobu Maeda ${ }^{1}$, Shintaro Minegishi ${ }^{1}$, Tomoaki Ishigami ${ }^{1}$, Yoshiyuki Toya ${ }^{1}$, Akio Yamashita ${ }^{3}$, \\ Satoshi Umemura ${ }^{1,4}$ and Kouichi Tamura ${ }^{1, *}$ \\ 1 Department of Medical Science and Cardiorenal Medicine, Yokohama City University Graduate School of \\ Medicine, 3-9 Fukuura, Kanazawa-ku, Yokohama 236-0004, Japan; t146017e@yokohama-cu.ac.jp (K.O.); \\ k_uneda@yokohama-cu.ac.jp (K.U.); t106048f@yokohama-cu.ac.jp (S.H.); \\ t136034d@yokohama-cu.ac.jp (R.K.); kspring00712@gmail.com (K.H.); ja472t@bma.biglobe.ne.jp (S.K.); \\ mmatsuda@yokohama-cu.ac.jp (M.M.); o.masato@gmail.com (M.O.); maeda_chigasaki@yahoo.co.jp (A.M.); \\ minegish@yokohama-cu.ac.jp (S.M.); tommmish@yokohama-cu.ac.jp (T.I.); ystoya@yokohama-cu.ac.jp (Y.T.); \\ umemuras@med.yokohama-cu.ac.jp (S.U.) \\ 2 Cardiovascular and Metabolic Disorders Program, Duke-NUS Medical School, 8 College Road, \\ Singapore 169857, Singapore \\ 3 Department of Molecular Biology, Yokohama City University Graduate School of Medicine, 3-9 Fukuura, \\ Kanazawa-ku, Yokohama 236-0004, Japan; yamasita@yokohama-cu.ac.jp \\ 4 Yokohama Rosai Hospital, 3211 Kozukue-cho, Kohoku-ku, Yokohama 222-0036, Japan \\ * Correspondence: hiro1234@yokohama-cu.ac.jp (H.W.); azushima@yokohama-cu.ac.jp (K.A.); \\ tamukou@med.yokohama-cu.ac.jp (K.T.); \\ Tel.: +81-45-787-2635 (H.W., K.A. \& K.T.); Fax: +81-45-701-3738 (H.W., K.A. \& K.T.) \\ + These authors contributed equally to this work.
}

Academic Editors: Anastasia Susie Mihailidou, Jan Danser, Sadayoshi Ito, Fumitoshi Satoh and Akira Nishiyama Received: 28 January 2017; Accepted: 16 March 2017; Published: 21 March 2017

Abstract: Activation of tissue renin-angiotensin system (RAS), mainly mediated by an angiotensin II (Ang II) type 1 receptor (AT1R), plays an important role in the development of obesity-related metabolic disorders. We have shown that AT1R-associated protein (ATRAP), a specific binding protein of AT1R, functions as an endogenous inhibitor to prevent excessive activation of tissue RAS. In the present study, we newly generated ATRAP/Agtrap-floxed (ATRAP $\mathrm{fl}^{\mathrm{fl}}$ ) mice and adipose tissue-specific ATRAP downregulated (ATRAPadipoq) mice by the Cre/loxP system using Adipoq-Cre. Using these mice, we examined the functional role of adipose ATRAP in the pathogenesis of obesity-related metabolic disorders. Compared with ATRAP $\mathrm{fl}^{\mathrm{fl}}$ mice, ATRAP ${ }^{\text {adipoq }}$ mice exhibited a decreased ATRAP expression in visceral white adipose tissue (WAT) and brown adipose tissue (BAT) by approximately $30 \%$ and $85 \%$, respectively. When mice were fed a high-fat diet, ATRAPfl/fl mice showed decreased endogenous ATRAP expression in WAT that was equivalent to ATRAPadipoq mice, and there was no difference in the exacerbation of dietary obesity and glucose and lipid metabolism. These results indicate that ATRAP in BAT does not influence the pathogenesis of dietary obesity or metabolic disorders. Future studies that modulate ATRAP in WAT are necessary to assess its in vivo functions in the development of obesity-related metabolic disorders.

Keywords: Cre/loxP; angiotensin; receptor; adipocyte; obesity 


\section{Introduction}

As the number of overweight and obese patients continues to increase worldwide, studies on the resulting health risks have gained significant attention [1,2]. Particularly, patients with excess visceral fat, such as those with metabolic syndrome, are at risk of developing a cardiovascular disease because of the acceleration of dyslipidemia and insulin resistance, as well as hypertension and type-2 diabetes mellitus [3-6]. Recent studies have focused on the pathological molecular mechanisms by which chronic adipose tissue inflammation and dysregulation of adipokines contribute to systemic insulin resistance in the progression of visceral fat obesity [7-9]. Previous studies demonstrated that the renin-angiotensin system (RAS), which is mainly mediated by the angiotensin II (Ang II) type-1 receptor (AT1R), plays an important role in obesity [10-12]. Angiotensin II type-1 receptor is involved in the regulation of physiological functions, including glucose metabolism, lipid metabolism, and adipogenesis [13]. Furthermore, the excessive activation of AT1R signaling increases oxidative stress and chronic inflammation, which results in the induction of insulin resistance. We have shown that AT1R-associated protein (ATRAP) directly binds to the C-terminus of AT1R. Angiotensin II type-1 receptor-associated protein promotes the constitutive internalization of AT1R, and is therefore likely to be an endogenous inhibitor that selectively prevents excessive activation of the AT1R signaling pathway. Angiotensin II type-1 receptor-associated protein and AT1R are endogenously expressed in many organs. Notably, adipose tissue shows high endogenous expression levels of ATRAP [14-17]. In our previous study, systemic ATRAP-knockout mice fed a high-fat diet (HFD) showed increased significant visceral fat, adipocyte hypertrophy, enhanced inflammation with macrophage infiltration of adipose tissue, and exacerbation of systemic insulin resistance compared with wild-type mice fed an HFD. Moreover, the transplantation of epididymal white adipose tissue (WAT), which highly expresses exogenous ATRAP, to systemic ATRAP knockout mice, caused a reduction in visceral fat and insulin resistance [16].

Here, we generated mice with suppressed adipose tissue-specific ATRAP expression to examine the functional role of adipose ATRAP in the pathogenesis of obesity-related metabolic disorders. To suppress ATRAP expression specifically in adipose tissue, we used mice expressing Cre recombinase with Cre/loxP system, which is driven by the adiponectin gene promoter [18]. When we generated mice where the ATRAP gene was recombined in adipocytes (ATRAPadipoq mice), they showed decreased ATRAP expression in the WAT and brown adipose tissue (BAT) by approximately $30 \%$ and $85 \%$,

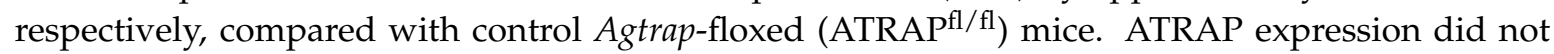
change in other analyzed organs. ATRAPl/fl mice fed an HFD showed decreased endogenous ATRAP expression in the WAT that was equivalent to ATRAPadipoq mice fed an HFD. No difference in the exacerbation of dietary obesity, and glucose and lipid metabolism disorders mediated by an HFD was observed between genotypes. These results suggest that ATRAP expression in BAT did not influence the pathogenesis of obesity-related metabolic disorders. Future studies that modulate ATRAP in WAT are necessary to assess the in vivo functions of ATRAP in WAT.

\section{Results}

\subsection{Generation of Adipose Tissue-Specific ATRAP Downregulated Mice}

To study the effect of ATRAP deletion in adipose tissue, we generated an Agtrap (angiotensin II receptor associated protein) gene "floxed" mouse (Agtrap flfl $)$ strain carrying the loxP-flanked Agtrap allele. Agtrap flfl mice were crossed with Adipoq-Cre transgenic mice that expressing Cre recombinase under control of the mouse adiponectin promoter [18]. The resulting Agtrap $p^{f / f l}$ / Adipoq-Cre mice were then mated with Agtrap flffl mice to generate Agtrap fl/fl /Adipoq-Cre (ATRAPadipoq) mice and control Agtrap ${ }^{f l f l}$ mice without Adipoq-Cre (ATRAP $\mathrm{fl}^{\mathrm{fl}}$ ). Figure 1A shows the strategy of conditional gene targeting for Agtrap. To verify the presence of loxP sites within the Agtrap gene of the generated mice, tail DNAs were analyzed by PCR amplification for the first loxP region in intron 2 and the second loxP region in intron 4. Similarly, Cre transgene was identified by PCR genotyping (Figure 1B). 
To confirm the efficiency and specificity of ATRAP downregulation in adipose tissue, we quantified the ATRAP mRNA abundance in each tissue from ATRAPadipoq and ATRAPfl/fl mice fed a low-fat diet (LFD) by real-time reverse transcription quantitative polymerase chain reaction (RT-qPCR) analysis. ATRAP $^{\text {adipoq }}$ mice expressed approximately a $30 \%$ reduction of ATRAP mRNA in the WAT and approximately an $85 \%$ reduction in the BAT compared with ATRAP ${ }^{\mathrm{fl} / \mathrm{fl}}$ mice, but no significant change in other tissues (Figure 1C). In addition, we examined ATRAP protein levels in the WAT and BAT from ATRAP $^{\text {adipoq }}$ and ATRAPfl/fl mice fed an LFD. Similarly, while ATRAPadipoq mice exhibited a mild decrease in protein levels of ATRAP expression in the WAT compared with ATRAP $\mathrm{fl}^{\mathrm{fl}}$ mice, these mice exhibited that a marked decrease in protein levels of ATRAP expression is the BAT (Figure 1D). Since ATRAP is associated with the deactivation of AT1R signaling, we further examined whether expression of other RAS components such as angiotensinogen and AT1R would be altered in the WAT and BAT of ATRAPadipoq mice. As shown in Figure 2, the mRNA expression levels of angiotensinogen and AT1R in the WAT and BAT of ATRAP adipoq mice were comparable with those in the WAT and BAT of ATRAPfl/fl mice.

A

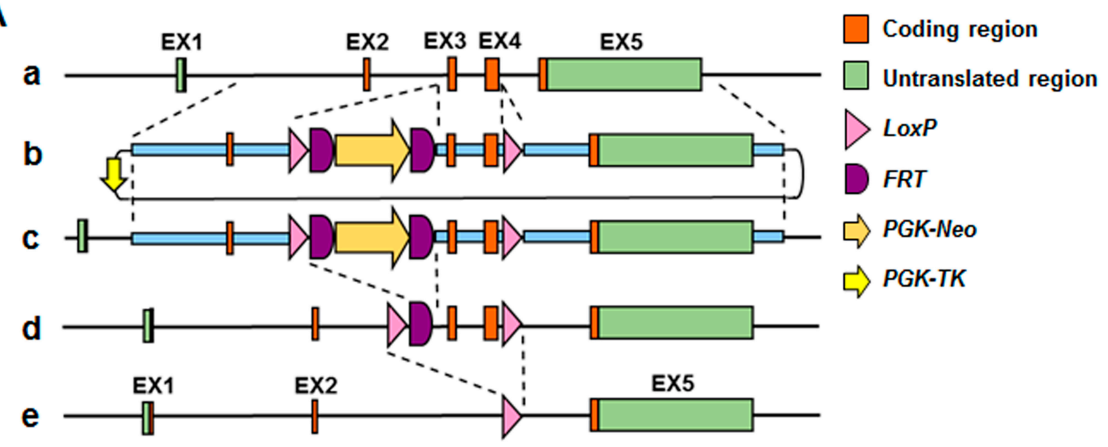

B

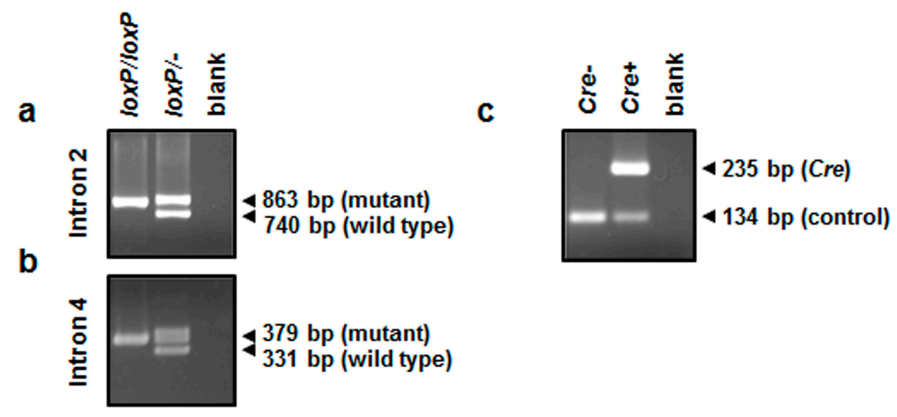

C

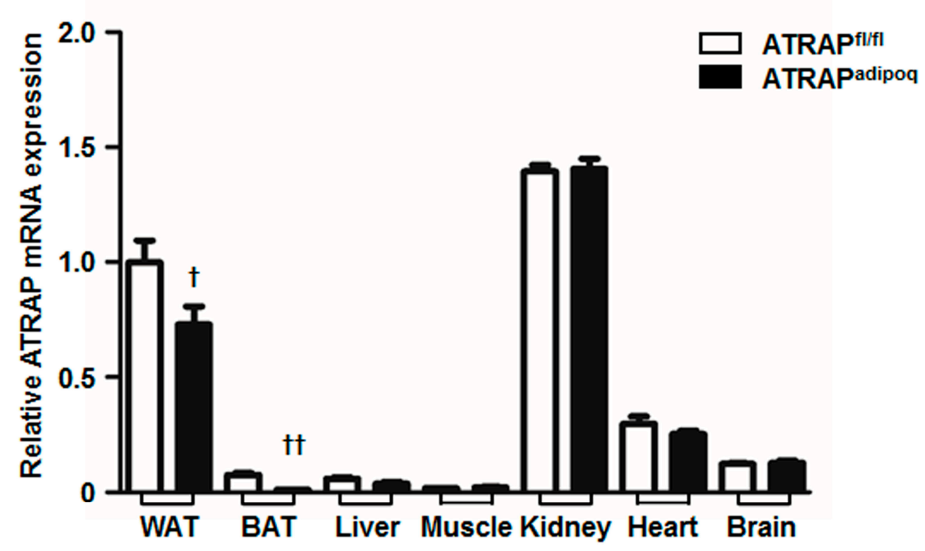

Figure 1. Cont. 
D
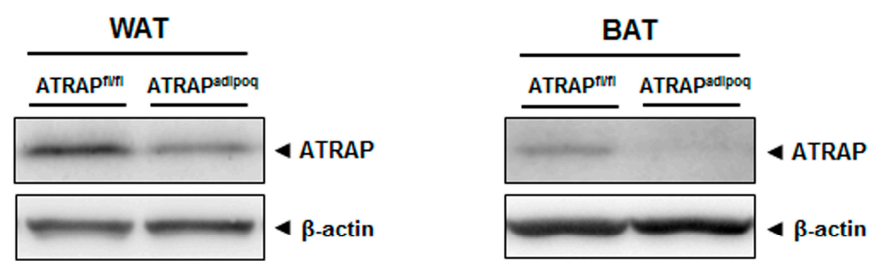

Figure 1. Generation of adipose tissue-specific angiotensin II type-1 receptor-associated protein (ATRAP) downregulated mice. (A) Schematic representation of Adipoq-Cre mediated recombination in adipocytes: (a) wild-type allele; (b) targeting vector; (c) targeted allele; (d) Flp recombinase-mediated allele; and (e) Cre-mediated allele. (B) Agarose-gel electrophoresis of PCR products amplified with following primer sets, (a) F23005 and R23744, (b) F24587 and R24917, and (c) Cre-fw and Cre-rw for Cre transgene, mAgtrapChIPF and mAgtrapChIPR for Agtrap gene as an internal control. These primer sequences are described in Table 1. (C) The relative ATRAP mRNA levels in each tissue (WAT, BAT, liver, muscle, kidney, heart, and brain) of ATRAP adipoq and ATRAP ${ }^{\mathrm{fl} / \mathrm{fl}}$ mice aged 19-24 weeks on an LFD $(n=3-10)$. (D) Representative Western blots of ATRAP protein expression in WAT and BAT of ATRAP ${ }^{\mathrm{fl} / \mathrm{fl}}$ mice on an LFD. Values are the means \pm standard error of the mean (SEM). ${ }^{\dagger} p<0.05$, ${ }^{++} p<0.01$ vs. ATRAPfl/fl mice. Data were analyzed by unpaired Student's $t$-test. EX: Exon; PGK-Neo: Phosphoglycerate kinase 1 promoter driven neomycin resistant gene; PGK-TK: Phosphoglycerate kinase 1 promoter driven SV40 thymidine kinase gene; WAT: White adipose tissue; BAT: Brown adipose tissue; LFD: Low-fat diet.
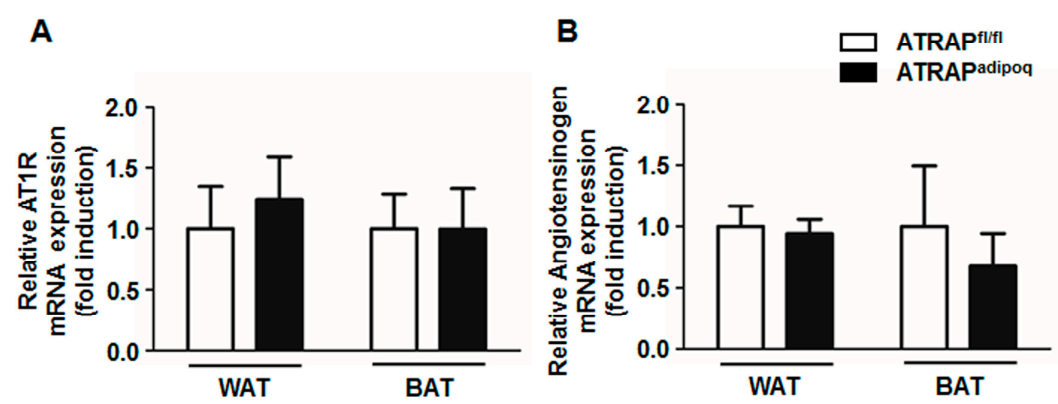

Figure 2. The relative expression of renin-angiotensin system (RAS) components in adipose tissues. Relative angiotensin II type-1 receptor (AT1R) mRNA (A) and angiotensinogen mRNA (B) expression in WAT and BAT of ATRAPl/fl and ATRAPadipoq mice fed an LFD $(n=5-6)$. Values are the means \pm standard error of the mean (SEM). AT1R: Angiotensin II type1 receptor; WAT: White adipose tissue; BAT: Brown adipose tissue; LFD: Low-fat diet.

Table 1. Primer sequences to generate Agtrap ${ }^{f l / f l}$ and Adipoq-Cre ${ }^{+} /$Agtrap $^{f l / f l}$ mice.

\begin{tabular}{|c|c|c|}
\hline Primer & Sequence $\left(5^{\prime}-3^{\prime}\right)$ & Target Region \\
\hline $\begin{array}{l}\text { F23005 } \\
\text { R23744 }\end{array}$ & $\begin{array}{l}\text { CCTCTTCTGGACCACTCTATCTCTCTGC } \\
\text { GTTCCAGGGTCTTAACCTCCTCTGAG }\end{array}$ & first loxP \\
\hline $\begin{array}{l}\text { F24587 } \\
\text { R24917 }\end{array}$ & $\begin{array}{l}\text { CTCGTCTACCACATGCACCGTCAACG } \\
\text { AGCTCCCATAGAATAGGTTCAGAGAGG }\end{array}$ & second $\operatorname{lox} P$ \\
\hline $\begin{array}{l}\text { cre-fw } \\
\text { cre-rw }\end{array}$ & $\begin{array}{l}\text { AGGTTCGTGCACTCATGGA } \\
\text { TCGACCAGTTTAGTTACCC }\end{array}$ & cre \\
\hline $\begin{array}{l}\text { mAgtrapChIPF } \\
\text { mAgtrapChIPR }\end{array}$ & $\begin{array}{l}\text { CCTAGCAGCAAGAGCAGCT } \\
\text { GAACTCGGGAACAAACTTCCT }\end{array}$ & agtrap \\
\hline $\begin{array}{l}\text { 5AF5 } \\
\text { neo108r }\end{array}$ & $\begin{array}{l}\text { AGTGAATTCATTATCTAGGGACAGAATTACAGG } \\
\text { CCTCAGAAGAACTCGTCAAGAAG }\end{array}$ & $5^{\prime}$-targeted allele (1st) \\
\hline $\begin{array}{l}\text { 5AF4 } \\
\text { neo100 }\end{array}$ & $\begin{array}{l}\text { AGTGAATTCAGGTCAGGCTCTGCCTTATTCTGC } \\
\text { AGGTGAGATGACAGGAGATC }\end{array}$ & $5^{\prime}$-targeted allele (nested) \\
\hline $\begin{array}{l}\text { neo_marker_sense } \\
\text { 3AR2 }\end{array}$ & $\begin{array}{l}\text { ATTCGCAGCGCATCGCCTTCTATCGCCTTC } \\
\text { TAAGCGGCCGCTCTCCCCAGAAATAGCTGGAAATCACC }\end{array}$ & $3^{\prime}$-targeted allele \\
\hline
\end{tabular}




\subsection{Physiological and Metabolic Status of ATRAPadipoq Mice}

\subsubsection{Body Weight Changes and Physiologic Parameters}

At baseline, there were no significant differences in body weight, systolic blood pressure, heart rate, rectal temperature, tissue weight, and plasma physiological parameters between the ATRAPl/fl and ATRAPadipoq mice on the LFD (Table 2). High-fat diet loading for 16 weeks significantly increased body weight in both genotypes to similar degrees (Figure 3). The WAT, BAT, and liver weight were similarly increased by an HFD in both types of mice (Table 2). The systolic blood pressure (SBP) of ATRAPfl/fl mice was significantly increased by an HFD. ATRAPadipoq mice had no significant increase of SBP

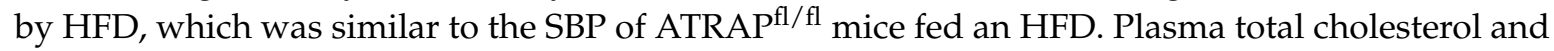
insulin concentrations were significantly increased by HFD in both types of mice. However, there were no significant differences between the two genotypes (Table 2). Although only ATRAPadipoq mice had an increased plasma glucose concentration by HFD, there was no significant difference between genotypes on either diet (Table 2).

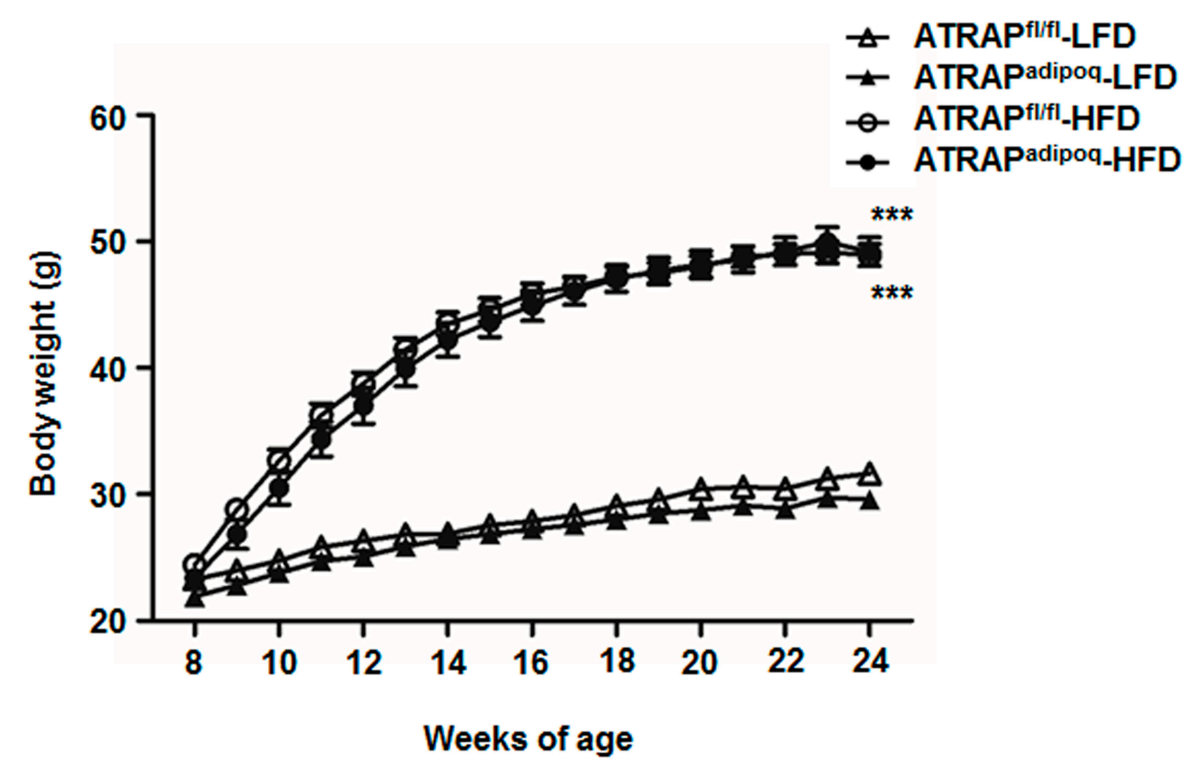

Figure 3. Change in body weight in ATRAPl/fl and ATRAPadipoq mice fed an LFD or HFD $(n=9)$. $\Delta$, ATRAP $^{\mathrm{fl} / \mathrm{fl}}$ mice fed an LFD; $\boldsymbol{\Lambda}$, ATRAPadipoq mice fed an LFD; $\bigcirc, \mathrm{ATRAP}^{\mathrm{fl} / \mathrm{fl}}$ mice fed an HFD; •, ATRAPadipoq mice fed an HFD. Values are the means \pm SEM. ${ }^{* * *} p<0.001$ vs. LFD within the same group. Data were analyzed by two-way repeated measures analysis of variance (ANOVA). LFD: Low-fat diet; HFD: High-fat diet.

Table 2. Physiological and metabolic parameters of mice on a low-fat diet or high-fat diet.

\begin{tabular}{|c|c|c|c|c|}
\hline \multirow{2}{*}{ Variables } & \multicolumn{2}{|c|}{ LFD } & \multicolumn{2}{|c|}{ HFD } \\
\hline & ATRAP $P^{f l / f l}$ & ATRAP ${ }^{\text {adipoq }}$ & ATRAP $P^{f l / f l}$ & ATRAP ${ }^{\text {adipoq }}$ \\
\hline Body weight $(\mathrm{g})$ & $31.6 \pm 0.6$ & $29.5 \pm 0.5$ & $48.9 \pm 0.8^{* * *}$ & $49.1 \pm 1.1^{* * *}$ \\
\hline Systolic blood pressure $(\mathrm{mmHg})$ & $114 \pm 1$ & $116 \pm 1$ & $124 \pm 2 *$ & $124 \pm 3$ \\
\hline Heart rate (beat $/ \mathrm{min}$ ) & $742 \pm 1$ & $747 \pm 15$ & $712 \pm 8$ & $743 \pm 11$ \\
\hline Rectal temperature $\left({ }^{\circ} \mathrm{C}\right)$ & $37.2 \pm 0.2$ & $37.8 \pm 0.3$ & $37.8 \pm 0.1$ & $37.7 \pm 0.1$ \\
\hline \multicolumn{5}{|l|}{ Tissue weight } \\
\hline Epididymal adipose tissue (mg) & $872 \pm 160$ & $694 \pm 144$ & $1293 \pm 25^{* * *}$ & $1220 \pm 48^{* * *}$ \\
\hline Brown adipose tissue $(\mathrm{mg})$ & $139 \pm 14$ & $128 \pm 7$ & $425 \pm 27^{* * *}$ & $404 \pm 22^{* * *}$ \\
\hline Liver (mg) & $1510 \pm 127$ & $1407 \pm 50$ & $3670 \pm 226^{* * *}$ & $3242 \pm 192 * * *$ \\
\hline Heart (mg) & $148 \pm 9$ & $139 \pm 7$ & $156 \pm 6$ & $145 \pm 4$ \\
\hline
\end{tabular}


Table 2. Cont.

\begin{tabular}{|c|c|c|c|c|}
\hline \multirow{2}{*}{ Variables } & \multicolumn{2}{|c|}{ LFD } & \multicolumn{2}{|c|}{ HFD } \\
\hline & ATRAPfl/fl & ATRAPadipoq & ATRAP fl/fl & ATRAPadipoq \\
\hline \multicolumn{5}{|l|}{ Plasma concentration } \\
\hline Total cholesterol (mg/dL) & $83 \pm 8$ & $91 \pm 6$ & $250 \pm 16^{* * *}$ & $218 \pm 12 * * *$ \\
\hline Triglyceride (mg/dL) & $35 \pm 9$ & $38 \pm 8$ & $35 \pm 4$ & $22 \pm 1$ \\
\hline Non-esterified fatty acid $(\mu \mathrm{Eq} / \mathrm{L})$ & $470 \pm 147$ & $496 \pm 143$ & $456 \pm 94$ & $241 \pm 42$ \\
\hline Glucose $(\mathrm{mg} / \mathrm{dL})$ & $232 \pm 16$ & $206 \pm 11$ & $259 \pm 19$ & $288 \pm 25 *$ \\
\hline Insulin (ng/mL) & $1.3 \pm 0.2$ & $1.3 \pm 0.1$ & $8.1 \pm 1.7^{* *}$ & $7.1 \pm 2.2 *$ \\
\hline
\end{tabular}

All of the values are the means \pm SEM. ${ }^{*} p<0.05,{ }^{* *} p<0.01,{ }^{* * *} p<0.001$ vs. LFD within the same group. $n=6-12$ per group. Data were analyzed by two-way ANOVA. ATRAPfl/fl: Agtrap-floxed control mice; ATRAPadipoq: Agtrap-floxed with Adipoq-Cre transgenic mice; LFD: Low-fat diet; HFD: High-fat diet.

\subsubsection{Glucose and Insulin Tolerance}

To examine the effects of adipose ATRAP downregulation on insulin resistance, we performed a glucose tolerance test (GTT) and an insulin tolerance test (ITT), which reflect the glucose tolerance and insulin sensitivity, respectively. There were no significant differences in GTT between the ATRAPl/fl and ATRAP adipoq mice fed an LFD. High-fat diet loading for 16 weeks significantly exacerbated glucose intolerance in the ATRAP ${ }^{\mathrm{fl} / \mathrm{fl}}$ and ATRAPadipoq mice. However, there were no significant differences in glucose intolerance between the genotypes (Figure 4A,C). Similarly, the ITT showed that HFD significantly exacerbated insulin resistance in both types of mice to similar degrees (Figure 4B,D).
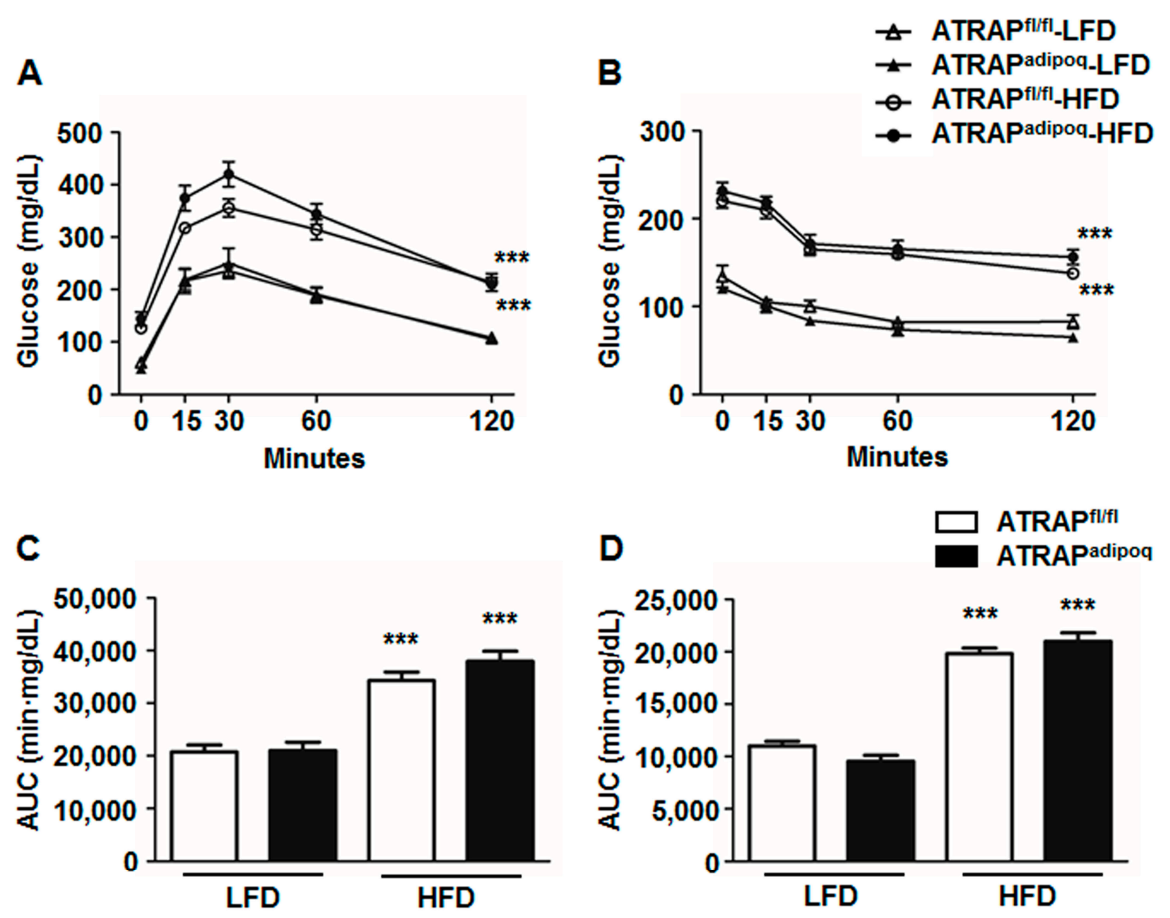

Figure 4. Glucose tolerance test (GTT) and insulin tolerance test (ITT). (A,B) The GTT and ITT in $\mathrm{ATRAP}^{\mathrm{fl} / \mathrm{fl}}$ and ATRAP ${ }^{\text {adipoq }}$ mice after 16-week LFD or HFD feeding $(n=5-15) . \Delta, \mathrm{ATRAP}^{\mathrm{fl} / \mathrm{fl}}$ mice

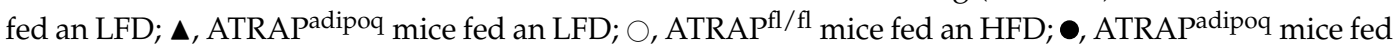
an HFD; (C,D) The area under the curve (AUC) of GTT and ITT in ATRAPl/fl and ATRAPadipoq mice after 16-week LFD or HFD feeding $(n=5-15)$. Values are the means \pm SEM. $(\mathbf{A}, \mathbf{B}){ }^{* * *} p<0.001$ vs. LFD within the same group. Data were analyzed by two-way repeated measures ANOVA. (C,D) ${ }^{* * *} p<0.001$ vs. LFD within the same group. Data were analyzed by two-way ANOVA. LFD: Low-fat diet; HFD: High-fat diet. 
2.3. Effects of High-Fat Diet on Adipocyte Hypertrophy and Macrophage Infiltration in ATRAPflfl and ATRAP ${ }^{\text {adipoq }}$ Mice

We next examined adipocyte morphology and inflammation in ATRAPfl/fl and ATRAPadipoq mice on LFD and HFD. The results of histological analysis showed that there were no differences in WAT adipocyte morphology between the ATRAPl/fl and ATRAPadipoq mice fed an LFD. High-fat diet loading for 16 weeks caused adipocyte hypertropy in both types of mice, to the same extent (Figure 5A). In addition, we examined inflammation-related gene expressions in WAT of ATRAPfl/fl and ATRAPadipoq mice. High-fat diet loading for 16 weeks significantly increased mRNA expression of F4/ 80 and monocyte chemotactic protein-1 (MCP-1), markers of macrophage infiltration, in WAT. However, there were no significant differences in the upregulation of these genes in response to HFD between the genotypes (Figure 5B).

A

LFD

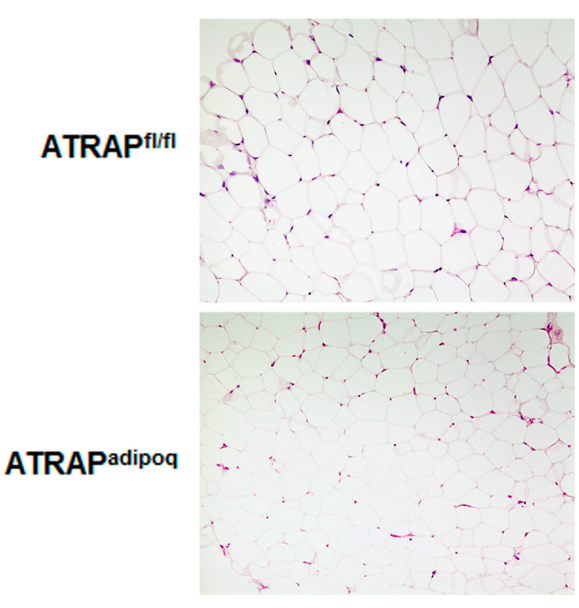

B

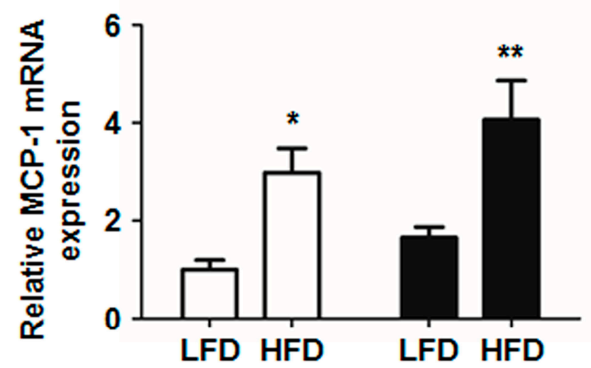

HFD

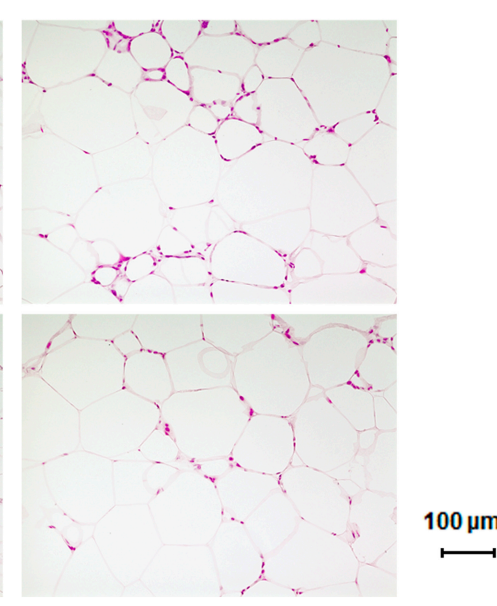

$00 \mu \mathrm{m}$

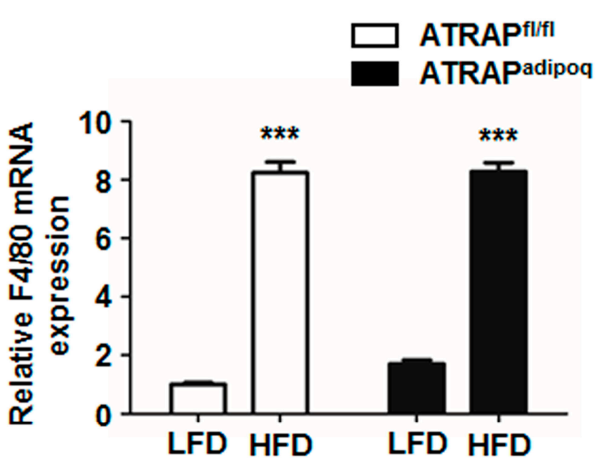

Figure 5. Adipocyte morphology and inflammation of WAT. (A) Representative images of adipocyte cells in WAT of ATRAPflfl and ATRAPadipoq mice fed an LFD and HFD. (B) Relative monocyte chemotactic protein-1 (MCP-1) and F4/80 mRNA expression in WAT of ATRAPfl/fl and ATRAPadipoq mice fed an LFD and HFD ( $n=5-6)$. Values are the means \pm SEM. ${ }^{*} p<0.05,{ }^{* *} p<0.01,{ }^{* * *} p<0.001$ vs. LFD within the same group. Data were analyzed by two-way ANOVA. LFD: Low-fat diet; HFD: High-fat diet.

2.4. White Adipose Tissue ATRAP mRNA Expression in ATRAPadipoq Mice Is Comparable to ATRAPflfl Mice on a High-Fat Diet

Because there were no differences in physiological and metabolic parameters, adipocyte morphology, and adipose macrophage infiltration between the ATRAP fl/fl and ATRAPadipoq mice on HFD or LFD, we examined the ATRAP mRNA expression in the WAT. As shown in Figure 6A, 
ATRAP mRNA levels in the WAT from ATRAPadipoq mice were reduced by about $30 \%$ compared with ATRAP $\mathrm{fl} / \mathrm{fl}$ mice on LFD similar to that observed for the tissue distribution of ATRAP mRNA expression (Figure 1C). High-fat diet for 16 weeks significantly decreased WAT ATRAP mRNA expression in ATRAP $^{\text {fl/fl }}$ mice, but not ATRAPadipoq mice. There were no significant differences in WAT ATRAP mRNA expression between ATRAPl/fl and ATRAPadipoq mice fed an HFD (Figure 6A). In contrast, ATRAP mRNA levels in the BAT from ATRAP adipoq mice were markedly decreased compared with ATRAP ${ }^{\mathrm{fl} / \mathrm{fl}}$ mice either on LFD or HFD (Figure 6B). In addition, we examined whether endogenous ATRAP mRNA expression is changed by HFD loading in tissues other than adipose tissue. In liver, HFD for 16 weeks significantly decreased ATRAP mRNA expression in ATRAP ${ }^{\mathrm{fl} / \mathrm{fl}}$ mice (Figure 6C).

\section{A}

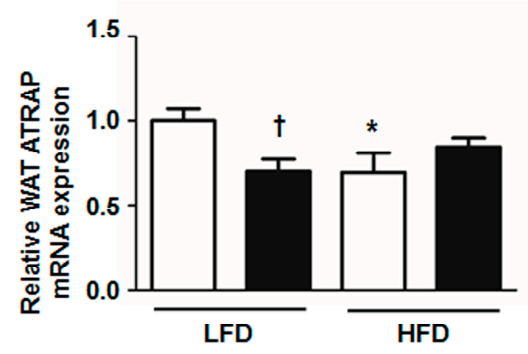

C

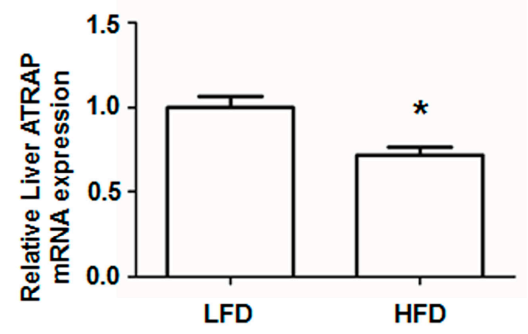

B

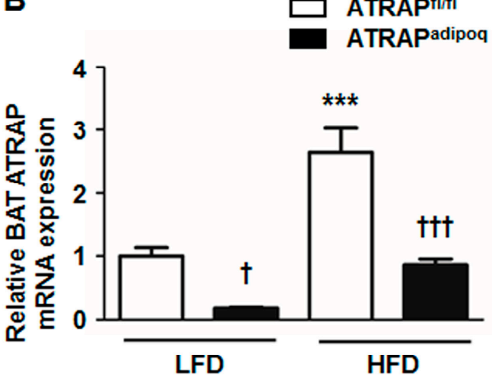

Figure 6. The changes of ATRAP expression in adipose tissues and liver with HFD. (A) Relative WAT ATRAP mRNA expression in ATRAP $\mathrm{Pl}^{\mathrm{fl} \mathrm{fl}}$ and ATRAPadipoq mice fed an LFD and HFD $(n=6)$. (B) Relative BAT ATRAP mRNA expression in ATRAP ${ }^{\mathrm{fl} / \mathrm{fl}}$ and ATRAP ${ }^{\text {adipoq }}$ mice fed an LFD and $\operatorname{HFD}(n=6)$. Relative liver ATRAP mRNA expression in ATRAPl/fl mice fed an LFD and HFD $(n=6)$. Values are the means \pm SEM. $(\mathrm{A}, \mathrm{B})^{\dagger} p<0.05,{ }^{++\dagger} p<0.001 \mathrm{vs}$. ATRAP ${ }^{\mathrm{fl} / \mathrm{fl}}$ mice on the same diet. ${ }^{*} p<0.05,{ }^{* * *} p<0.001$ vs. LFD within the same group. Data were analyzed by two-way ANOVA. (C) ${ }^{*} p<0.05$ vs. LFD group. Data were analyzed by an unpaired Student's $t$-test. LFD: Low-fat diet; HFD: High-fat diet.

\section{Discussion}

Six major findings were obtained in our study: (i) the rate of decrease in ATRAP mRNA in ATRAPadipoq mice generated using the Adipoq-Cre line with the Cre/loxP system was approximately $30 \%$ in the WAT and $85 \%$ in the BAT fed an LFD; (ii) an HFD significantly decreased endogenous ATRAP expression in the WAT and liver in Agtrap-floxed mice, concomitant with an increase in dietary obesity and insulin resistance; (iii) ATRAP expression in the WAT was similar between ATRAPadipoq and ATRAPfl/fl mice when fed an HFD; (iv) ATRAP expression in the BAT from ATRAPadipoq mice was markedly decreased compared with ATRAPfl/fl mice even when fed an HFD; (v) no significant difference was observed in glucose and lipid metabolism in ATRAPadipoq and ATRAPl/fl mice fed an HFD; and (vi) ATRAP expression in the BAT did not appear to influence the pathogenesis of obesity-related metabolic disorders.

We used the Adipoq-Cre line to generate mice in which target genes were knocked out specifically in adipose tissues [18]. The $a \mathrm{P} 2$-Cre line created by multiple laboratories has had a major role in the 
generation of mouse models in which adipose tissue-specific genes were knocked out. However, problems such as the endogenous expression of fatty acid binding protein 4 (FABP4) in macrophages, vascular endothelial cells, and ectopic Cre expression in blood cells, heart, and skeletal muscle, have been identified [19-21]. In contrast, the Adipoq-Cre line was reported to be superior to the aP2-Cre line regarding adipocyte specificity $[22,23]$. Therefore, we chose the Adipoq-Cre line to localize Cre-dependent gene recombination to the adipose tissue (adipocytes). However, the decrease in ATRAP mRNA expression in the WAT of ATRAPadipoq mice was unexpectedly mild. Recombination sensitivity mediated by Cre, which differs substantially depending on the target gene locus, was likely one of the reasons for this mild decrease [22,24,25]. Similar to our study, several gene-modified models generated using the Adipoq-Cre line showed poor recombination efficiency in the WAT compared with the BAT [22]. Indeed, recombination efficiency is dependent on adipose tissue type, e.g., perigonadal adipose tissue (visceral fat tissue), subcutaneous adipose tissue, and BAT. In addition, other non-adipocyte cells in adipose tissue might express high levels of ATRAP, such as macrophages. Therefore, further studies will be needed to compare ATRAP expression in adipocytes and stromal vascular fractions isolated from WAT between ATRAPadipoq and ATRAPl/fl mice.

ATRAP selectively prevents the excessive activation of the AT1R signaling pathway by various pathological stimuli. We previously reported the in vivo regulation of ATRAP expression. The relative expression of ATRAP to AT1R in the heart of spontaneously hypertensive rats (SHRs) was decreased as hypertension and cardiac hypertrophy progressed [26]. In Dahl salt-sensitive rats, high-salt diet loading decreased renal ATRAP expression and accelerated the progression of hypertensive kidney injury [27]. Expression of ATRAP in the WAT was decreased in KKAy mice, a diabetes mellitus model, compared with control C57BL/6N mice [16]. We also reported changes in tissue ATRAP expression in response to a pathological stimulus. For example, chronic Ang II infusion in mice decreased ATRAP expression in the kidney and heart and accelerated the progression of hypertension and cardiac hypertrophy $[28,29]$. In mice that underwent unilateral ureteral obstruction, renal ATRAP expression was decreased as renal fibrosis progressed [30]. In the present study, we determined that HFD loading in ATRAP $\mathrm{fl}^{\mathrm{f} / \mathrm{fl}}$ mice decreased endogenous ATRAP expression in the WAT and exacerbated the progression of dietary obesity and insulin resistance. This finding suggests that endogenous ATRAP alone is likely insufficient to suppress lifestyle diseases, such as metabolic syndrome, because its expression is decreased by pathological stimuli.

ATRAPadipoq mice showed a phenotype similar to that of ATRAP ${ }^{\mathrm{f} 1 / \mathrm{f} 1}$ mice fed an LFD or HFD. Because ATRAP does not modulate the physiological AT1R signaling pathway in the absence of pathological stimuli, no clear difference was expected between genotypes fed an LFD [16]. However, even dietary obesity induced by an HFD did not result in differences in glucose or lipid metabolism between ATRAPadipoq and ATRAP $1 / \mathrm{f1}$ mice. This finding can be explained by the fact that HFD loading on ATRAP ${ }^{\mathrm{fl} / \mathrm{fl}}$ mice decreased the endogenous ATRAP expression level in the WAT, thus negating the difference in ATRAP expression levels between the genotypes. ATRAP function in the WAT of ATRAPadipoq mice is likely to be similar to that in ATRAP ${ }^{\mathrm{f} 1 / \mathrm{f} 1}$ mice because of the similar Expression levels of ATRAP mRNA in the WAT between the genotypes when fed an HFD. Moreover, dietary obesity altered the WAT composition-adipocytes and stromal vascular cells (SVC) including macrophages - and induced angiogenesis [9]. In fact, HFD loading caused adipocyte hypertrophy and macrophage infiltration in WAT of mice in the present study. However, recombination by Adipoq-Cre specifically targets adipocytes, but not SVC [21,22]. In this regard, further studies will be needed to investigate ATRAP expression in adipocytes and SVC isolated from WAT.

Brown adipose tissue acts antagonistically on dietary obesity by promoting thermogenesis, mainly by uncoupling protein-1 production, which, in turn, accelerates energy metabolism [31]. In the present study, ATRAP expression in the BAT was markedly decreased in ATRAPadipoq mice compared with ATRAPfl/fl mice. We also showed that ATRAP expression in BAT was significantly increased by HFD feeding in mice. Although the reasons for increasing ATRAP expression in BAT by HFD feeding are unclear at present, importantly, ATRAPadipoq mice still exhibited a decreased level of 
ATRAP expression in BAT compared with ATRAP $\mathrm{fl}^{\mathrm{ffl}}$ mice when fed an HFD. Nevertheless, the rectal temperature was comparable between the two genotypes fed an LFD and an HFD. This result is not surprising considering the very low levels of ATRAP in BAT compared to WAT.

To further study in vivo ATRAP function in the WAT in terms of dietary obesity, our results suggest the use of a mouse model other than the adipose tissue-specific Cre line and changing the duration of diet loading. The candidate lines include adiponectin-CreERT (tamoxifen-inducible Cre) [21], an adiponectin-Cre line generated by Scherer et al. [32] with a high efficiency in Cre recombination, conventional aP2-Cre, and Retn-Cre-using a $33 \mathrm{~kb}$ fragment of the resistin (Retn) gene-recently reported by the laboratory of Lazar et al. [33]. Because HFD loading decreased endogenous ATRAP expression in the WAT of ATRAP ${ }^{\mathrm{fl} / \mathrm{fl}}$ mice, studies using an adipose tissue-specific ATRAP overexpression model are thought to be a useful study tool. Recently, we reported that adipose tissue-specific ATRAP transgenic mice exhibit a suppression of HFD-induced visceral obesity and insulin resistance [34]. Since the establishment of conditional knockouts using the Cre/loxP system, numerous studies have been published, indicating the importance and convenience of this approach. However, as noted in our study, experimental conditions such as diet can influence the characteristics of these animal models. Thus, researchers should be careful in their interpretation of results in this field.

\section{Materials and Methods}

\subsection{Animals and Animal Care}

This study was performed in accordance with the National Institutes of Health (NIH) "Guide for the Care and Use of Laboratory Animals." All animal studies were reviewed and approved by the Animal Studies Committee of Yokohama City University (Yokohama, Japan). The protocol code is FA-16-025 approved at March 31, 2016. The mice were housed in a controlled environment with a $12 \mathrm{~h}$ light-dark cycle at a temperature of $25{ }^{\circ} \mathrm{C}$ and were allowed free access to food and water. They were fed either an LFD (3.6 kcal/g; 13.3\% energy as fat; The Oriental Yeast Co., Ltd. Tokyo, Japan) or HFD (5.6 kcal/g; 60.0\% energy as fat) for 16 weeks beginning at 8 weeks of age, and their body weights were measured weekly. All experiments in this study were performed with Adipoq-Cre $e^{+} /$Agtrap flfl mice and littermate Agtrap ${ }^{f / f l}$ mice. At the end of the experimental period (24 weeks of age), mice were anesthetized with an intraperitoneal injection of pentobarbital and sacrificed in the fed state between 10:00 a.m.-2:00 p.m.

\subsection{Generation of Adipoq-Cre /Agtrap $^{\text {flflf }}$ Mice}

\subsubsection{Generation of Agtrap ${ }^{f l f l}$ Mice}

For conditional Agtrap gene targeting, we generated an Agtrap gene "floxed" mouse where two loxP sequences were inserted into the mouse Agtrap locus by homologous recombination (Figure 1A). This series of processes was performed by TransGenic Inc. (Fukuoka, Japan). To construct the targeting vector, a $4.2 \mathrm{~kb}$ mouse genomic fragment containing intron 1 , exon 2 and intron 2 , a $1.1 \mathrm{~kb}$ fragment containing intron 2, exon 3, intron 3, exon 4 and intron 4, and a $5.7 \mathrm{~kb}$ fragment containing intron 4, exon 5 and the $3^{\prime}$ region of the Agtrap gene were amplified by PCR from RENKA embryonic stem (ES) cell genomic DNA, the cell line was established by the laboratory of Sakimura et al. (Niigata, Japan) [35]. The $4.2 \mathrm{~kb}$ genomic fragment was cloned into a plasmid vector containing loxP sequences, a PGK-Neo cassette (phosphoglycerate kinase 1 promoter driven neomycin resistant gene) flanked by $F R T$ sequences as a positive selection marker, and a PGK-TK cassette (phosphoglycerate kinase 1 promoter driven SV40 thymidine kinase gene) as a negative selection marker. Then, the $1.1 \mathrm{~kb}$ genomic fragment was subcloned into the plasmid. Subsequently, a $5.7 \mathrm{~kb}$ genomic fragment was inserted into the plasmid. The resulting targeting vector contained a PGK-TK cassette, a $4.2 \mathrm{~kb} 5^{\prime}$ homologous arm, first loxP site, FRT-flanked PGK-Neo cassette, $1.1 \mathrm{~kb}$-floxed genomic region containing exons 3 and 4 of the Agtrap gene, second loxP site, and $5.7 \mathrm{~kb} \mathrm{3'}$ homologous arm. This targeting vector was linearized 
and introduced into RENKA ES cells (C57BL/6N) by electroporation. After selection using Geneticin, the resistant clones were isolated, and their DNAs were screened for homologous recombinant by nested PCR using the following primer sets: 5AF5 and neo108r for first amplification, and 5AF4 and neo100 for second amplification of nested PCR. Homologous recombinations (PCR-positive ES clone) were confirmed in four clones (\#a2927, \#a3006, \#a3007, \#a3008). PCR-positive ES clones were expanded, and isolated DNAs were further analyzed by PCR amplification using the following primer sets: 5AF4 and neo100 for $5^{\prime}$ amplification, neo marker sense and 3AR2 for $3^{\prime}$ amplification (Figure 7A), and F24587 and R24917 for amplification of the second loxP region (Figure 7B). There were two clones with loxP sites (\#a3006, a3008). Homologous recombination of these clones was confirmed by genomic Southern hybridization probed with a neomycin resistant gene. The predicted size was detected (Figure 8). Homologous recombinant ES cell clones (\#a3006, \#a3008) were aggregated with ICR 8 cell embryos to generate chimeric mice. Germline transmitted F1 heterozygous mice were obtained by crossing chimeric mice with a high contribution of the RENKA background with C57BL/6N mice. The targeted allele was identified by PCR with the following primer set: 5AF4 and neo100. To remove the PGK-Neo cassette, F1 heterozygous mice were crossed with B6; D2-Tg(CAG-Flp)18Imeg (obtained from the Center for Animal Resources and Development (CARD), Kumamoto, Japan) transgenic mice, which express Flp recombinase in germ cells. Floxed allele without a PGK-Neo cassette was identified with the following PCR primer set: F23005 and R23744 (Figure 9). The primer sequences are shown in Table 1. Obtained heterozygous floxed $\left(\right.$ Agtrap $\left.^{\mathrm{fl} /-}\right)$ mice were further mated with $A g$ trap $^{\mathrm{fl} /-}$ mice to generate homozygous floxed $\left(\right.$ Agtrap $\left.{ }^{f l f l}\right)$ mice.

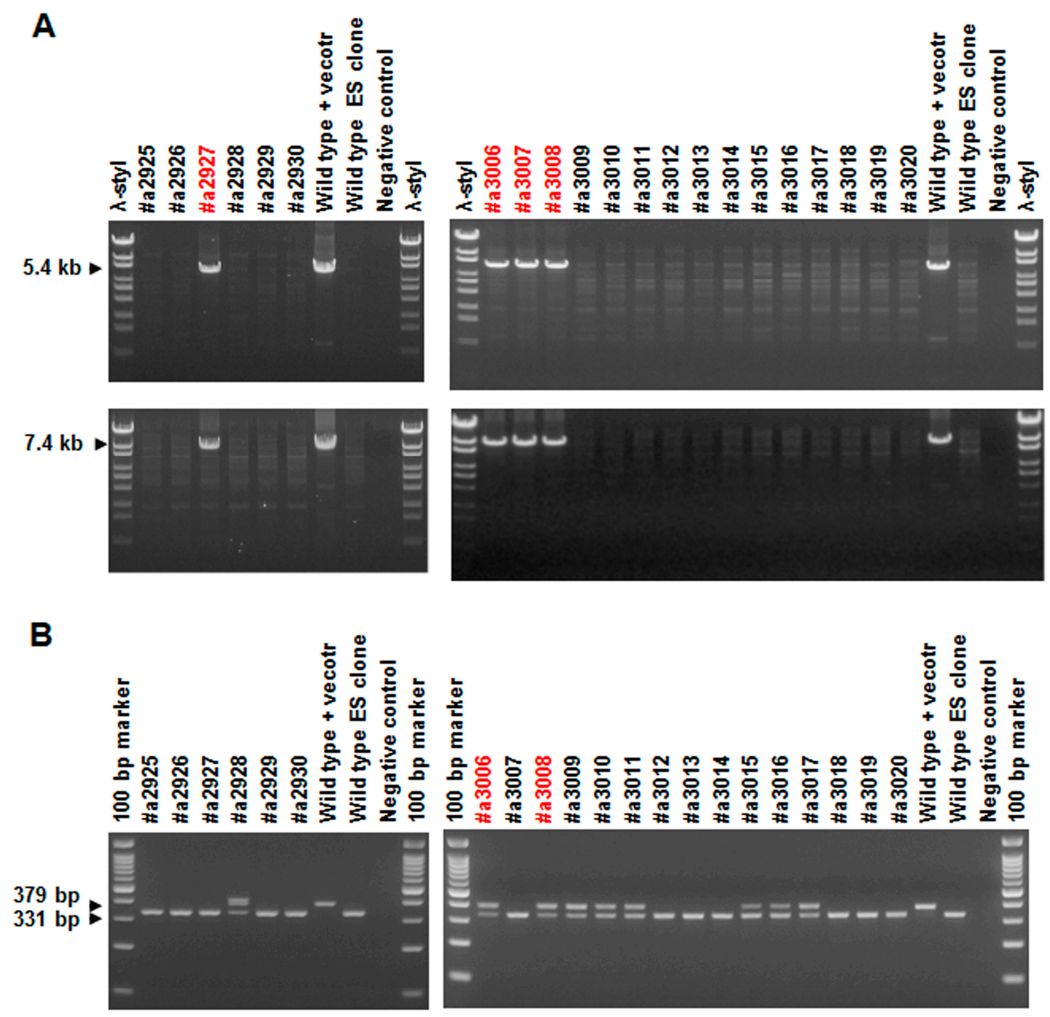

Figure 7. Agarose-gel electrophoresis of PCR products from embryonic stem (ES) cell clones' DNA (\#a2925-a2930, \#a3006-a3020), amplified for homologous recombination (A) and for detecting second loxP (B). (A) 5' PCR using primer set: 5AF4/neo100 (upper panel) and 3' PCR using primer set: neo marker sense/3AR2 (lower panel); red-labeled clones were positive for amplification. (B) PCR using primer set: F24587/R2491; red-labeled clones were positive for amplification of mutant loxP within positive for homologous recombination. 


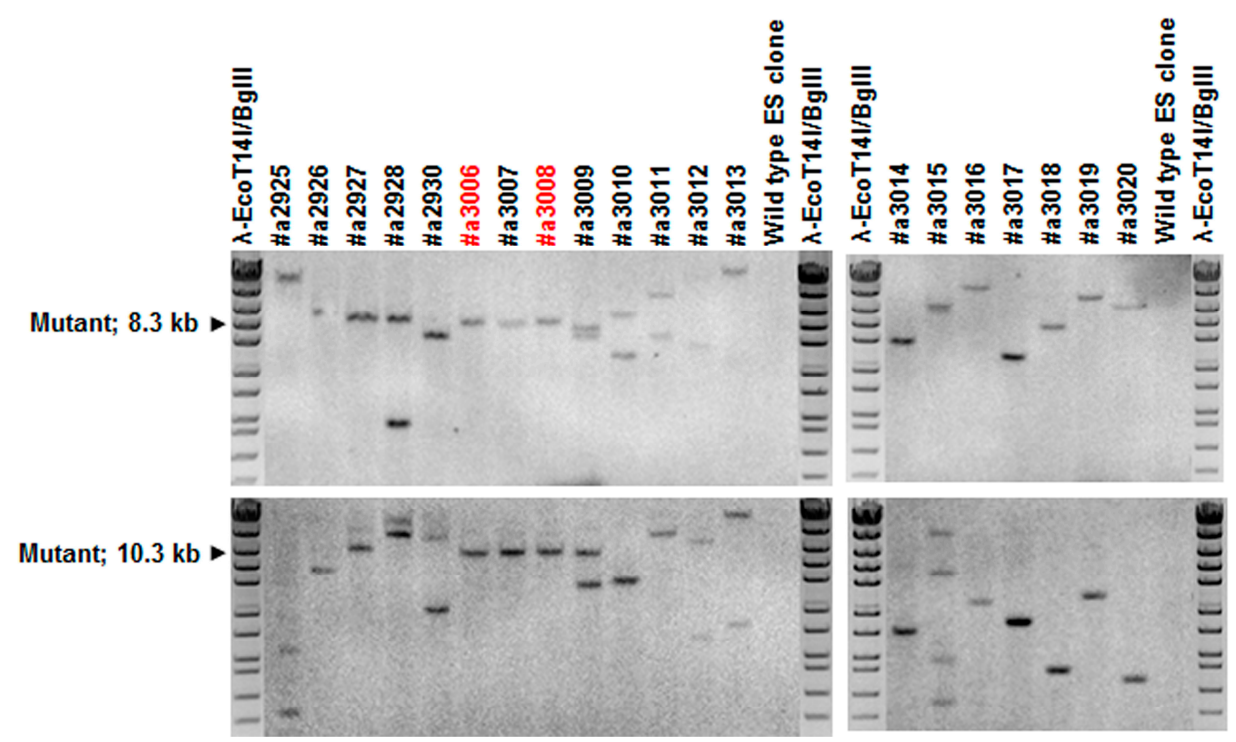

Figure 8. Southern blot analysis using neo probe. $5^{\prime}$ EcoRI-digested (target mutant band is $8.3 \mathrm{~kb}$ in upper panel) and $3^{\prime}$ NdeI-digested (target mutant band is $10.3 \mathrm{~kb}$ in lower panel) DNA were analyzed. $\#$ a3006 and \#a3008 clones (in red) were verified to have one inserted copy of the targeting vector.

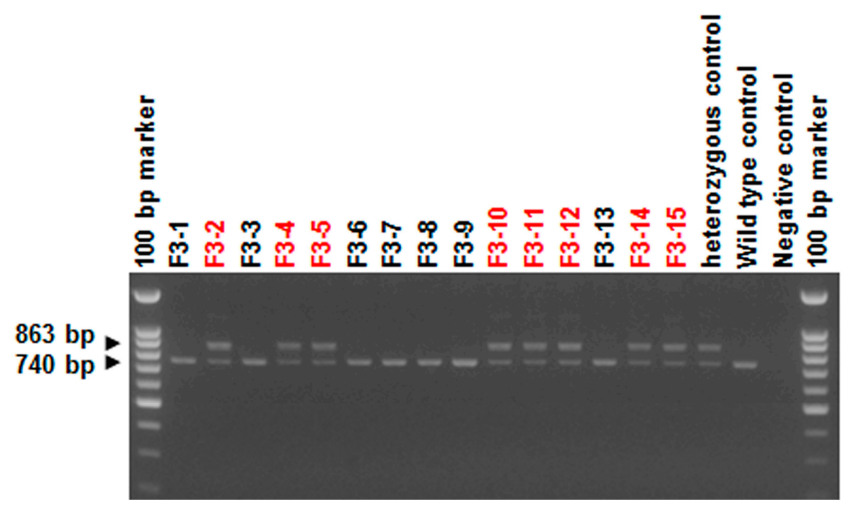

Figure 9. Agarose-gel electrophoresis of PCR products amplified to detect first loxP using the primer set F23005 and R23744. Analyzed DNAs (F3-1-F3-15) were from F3 mice with heterozygous Agtrap floxed allele from which the PGK-Neo cassette was removed. The red-labeled sample were positive for loxP site amplification.

\subsubsection{Generation of Adipoq-Cre ${ }^{+} /$Agtrap $^{f l f l}$ Mice}

To inactivate the Agtrap gene in adipocytes, Agtrap ${ }^{f l f l}$ mice were intercrossed with Adipoq-Cre transgenic mice expressing Cre recombinase under control of the mouse adiponectin promoter [18]. Adipoq-Cre transgenic mice were obtained from the Jackson Laboratory (Bar Harbor, Maine, USA). The resulting Adipoq-Cre $e^{+}$Agtrap ${ }^{f l f l}$ mice were mated with Agtrap fl/fl mice to generate Adipoq-Cre $/$ Agtrap $^{\text {fl/fl }}$ mice (ATRAPadipoq) and control Agtrap ${ }^{f l / f l}$ mice without Adipoq-Cre (ATRAPl/fl).

\subsection{Blood Pressure Measurement by the Tail-Cuff Method}

Systolic blood pressure and heart rate were measured by the tail-cuff method (BP-monitor MK-2000; Muromachi Kikai Co., Ltd., Tokyo, Japan) such that the blood pressure was measured without any preheating of the animals, as described previously [26,36]. All measurements were performed between 10:00 a.m.-2:00 p.m., with at least eight values taken for each measurement. 


\subsection{Biochemical Assay}

Blood samples were obtained by cardiac puncture when the mice were sacrificed in the fed state. Whole blood samples were centrifuged at $3000 \mathrm{rpm}$ (MR-150, Tomy Seiko Co., Ltd., Tokyo, Japan) at $4{ }^{\circ} \mathrm{C}$ for $15 \mathrm{~min}$ to separate the plasma. The resulting plasma was stored at $-80^{\circ} \mathrm{C}$ until use. Enzymatic assays were used to determine the plasma glucose, total cholesterol, triglycerides, and non-esterified fatty acids (Wako Pure Chemical, Osaka, Japan). The plasma insulin concentration was measured with a commercially available enzyme-linked immunosorbent assay (ELISA) kit (Morinaga Institute of Biological Science, Inc., Yokohama, Japan).

\subsection{Glucose and Insulin Tolerance Tests}

The GTT and ITT were performed as previously described with slight modifications [16]. Briefly, GTT and ITT were performed 4 days apart at the end of the experimental period between 10:00 a.m.-2:00 p.m. and 2:00 p.m.-4:00 p.m., respectively. For GTT, blood glucose concentrations were measured with a blood glucose test meter (Glutest Neo Super; Sanwa-Kagaku Co., Ltd., Nagoya, Japan) using blood samples taken from the tail tip of overnight-fasted mice at baseline and at 15, 30, 60 and $120 \mathrm{~min}$ after the intraperitoneal injection of glucose $(1 \mathrm{~g} / \mathrm{kg}$ body weight). For ITT, insulin $(0.75 \mathrm{U} / \mathrm{kg}$ body weight in $0.1 \%$ bovine serum albumin (BSA); Humulin R-Insulin; Eli Lilly and Co., Indiana, IN, USA) was administered via intraperitoneal injection after 4-h fasting. Blood glucose concentrations were measured at baseline and at 15, 30, 60 and 120 min after the injection.

\subsection{Real-Time RT-qPCR Analysis}

Total RNAs were extracted from the white adipose tissue with ISOGEN (Nippon Gene, Toyama, Japan) and the cDNA was synthesized using the SuperScript III First-Strand System (Invitrogen, Carlsbad, CA, USA). Real-time RT-qPCR was performed with an ABI PRISM 7000 Sequence Detection System (Applied Biosystems, Foster, CA, USA) by incubating the reverse transcription product with TaqMan PCR Master Mix and a designed Taqman probe (Applied Biosystems, Foster, CA, USA), as described previously [29]. The mRNA levels were normalized to those of the glyceraldehyde 3-phosphate dehydrogenase (GAPDH) control.

\subsection{Western Blot Analysis}

Western blot analysis was performed as described previously [28]. Briefly, total protein was extracted from WAT with a sodium dodecyl sulfate (SDS)-containing sample buffer. Then, the protein concentration of each sample was measured with a detergent compatible (DC) protein assay kit (Bio-Rad, Hercules, CA, USA) using bovine serum albumin as the standard. Equal amounts of protein extract were fractionated on a $5 \%-20 \%$ polyacrylamide gel (ATTO) and then transferred to a polyvinylidene difluoride (PVDF) membrane using the iBlot Dry Blotting System (Invitrogen). Membranes were blocked for $1 \mathrm{~h}$ at room temperature with phosphate-buffered saline (PBS) containing $5 \%$ skim milk powder and probed overnight at $4{ }^{\circ} \mathrm{C}$ with specific primary antibodies to ATRAP.

\subsection{Histological Analysis}

The epididymal WAT was collected and fixed with $10 \%$ paraformaldehyde overnight and embedded in paraffin. Tissue sections were stained with hematoxylin and eosin as described previously [16]. All images were acquired using a BZ-9000 microscope (Keyence, Osaka, Japan).

\subsection{Statistical Analysis}

All data are shown as the mean \pm standard error of the mean (SEM). Differences were analyzed as follows. A two-way analysis of variance (ANOVA) with a Bonferroni post-test was used to test for differences in diet within each genotype or differences in genotype for mice on the same diet. 
A two-way repeated measure ANOVA was used to test for differences over time. An unpaired Student's $t$-test was used to test for differences between two groups.

\section{Conclusions}

In conclusion, we report that wild-type mice fed an HFD showed decreased endogenous ATRAP expression in the WAT concomitant with the enhanced progression of dietary obesity and insulin resistance. Expression of ATRAP mRNA in the BAT was decreased by approximately $85 \%$ in mice with suppressed adipose tissue-specific ATRAP expression generated with the Cre/loxP system and the Adipoq-Cre line, compared with Agtrap-floxed control mice. Expression of ATRAP mRNA in the WAT of Agtrap gene-modified mice was decreased by approximately $30 \%$ at baseline of LFD but was similar to control mice after HFD loading. No significant difference between genotypes was detected regarding glucose and lipid metabolism after HFD loading. Overall, the results of the present study indicate that ATRAP expression in BAT does not influence the development of HFD-induced metabolic disorders.

Acknowledgments: This work was supported by grants from the Yokohama Foundation for advancement of Medical Science (to Hiromichi Wakui, Satoshi Umemura, and Kouichi Tamura), by a Grant-in-Aid from the The Cardiovascular Research Fund (to Kengo Azushima), by an Uehara Memorial Foundation grant (to Hiromichi Wakui), a Health and Labor Sciences Research grant (to Kouichi Tamura), grants-in-aid for Scientific Research from the Japan Society for the Promotion of Science (to Hiromichi Wakui, Kengo Azushima, Masato Ohsawa, and Kouichi Tamura), grants from SENSHIN Medical Research (to Hiromichi Wakui and Kouichi Tamura), the Banyu Life Science Foundation International (to Hiromichi Wakui and Kouichi Tamura), and the Salt Science Research Foundation (to Hiromichi Wakui and Kouichi Tamura).

Author Contributions: Kohji Ohki, Hiromichi Wakui, Kengo Azushima and Kouichi Tamura designed and conducted the research. Kohji Ohki, Hiromichi Wakui, Kengo Azushima, and Kouichi Tamura wrote the manuscript. Kohji Ohki, Hiromichi Wakui, Kengo Azushima, Kazushi Uneda, Sona Haku, Ryu Kobayashi, Kotaro Haruhara, Sho Kinguchi, Miyuki Matsuda, Masato Ohsawa, Akinobu Maeda and Shintaro Minegishi performed the experiments. Kohji Ohki, Hiromichi Wakui, Kengo Azushima, Akio Yamashita, and Yoshiyuki Toya analyzed the data. Tomoaki Ishigami and Satoshi Umemura supervised the research. All authors approved the final manuscript.

Conflicts of Interest: The authors declare no conflict of interest.

\section{Abbreviations}

$\begin{array}{ll}\text { Adipoq } & \text { Adiponectin gene } \\ \text { Agtrap } & \text { ATRAP gene } \\ \text { AT1R } & \text { Angiotensin II type 1 receptor } \\ \text { ATRAP } & \text { Angiotensin II type 1 receptor associated protein } \\ \text { BAT } & \text { Brown adipose tissue } \\ \text { GTT } & \text { Glucose tolerance test } \\ \text { HFD } & \text { High-fat diet } \\ \text { ITT } & \text { Insulin tolerance test } \\ \text { LFD } & \text { Low-fat diet } \\ \text { MCP-1 } & \text { Monocyte chemotactic protein-1 } \\ \text { WAT } & \text { White adipose tissue }\end{array}$

\section{References}

1. NCD Risk Factor Collaboration (NCD-RisC). Trends in adult body-mass index in 200 countries from 1975 to 2014: A pooled analysis of 1698 population-based measurement studies with $19 \cdot 2$ million participants. Lancet 2016, 387, 1377-1396.

2. Global BMI Mortality Collaboration. Body-mass index and all-cause mortality: Individual-participant-data meta-analysis of 239 prospective studies in four continents. Lancet 2016, 388, 776-786.

3. Zhang, M.; Hu, T.; Zhang, S.; Zhou, L. Associations of Different Adipose Tissue Depots with Insulin Resistance: A Systematic Review and Meta-analysis of Observational Studies. Sci. Rep. 2015, 5, 18495. [CrossRef] [PubMed] 
4. Van Gaal, L.F.; Mertens, I.L.; de Block, C.E. Mechanisms linking obesity with cardiovascular disease. Nature 2006, 444, 875-880. [CrossRef] [PubMed]

5. Aune, D.; Sen, A.; Norat, T.; Janszky, I.; Romundstad, P.; Tonstad, S.; Vatten, L.J. Body Mass Index, Abdominal Fatness, and Heart Failure Incidence and Mortality: A Systematic Review and Dose-Response Meta-Analysis of Prospective Studies. Circulation 2016, 133, 639-649. [CrossRef] [PubMed]

6. Mottillo, S.; Filion, K.B.; Genest, J.; Joseph, L.; Pilote, L.; Poirier, P.; Rinfret, S.; Schiffrin, E.L.; Eisenberg, M.J. The metabolic syndrome and cardiovascular risk a systematic review and meta-analysis. J. Am. Coll. Cardiol. 2010, 56, 1113-1132. [CrossRef] [PubMed]

7. Chawla, A.; Nguyen, K.D.; Goh, Y.P. Macrophage-mediated inflammation in metabolic disease. Nat. Rev. Immunol. 2011, 11, 738-749. [CrossRef] [PubMed]

8. Fuster, J.J.; Ouchi, N.; Gokce, N.; Walsh, K. Obesity-Induced Changes in Adipose Tissue Microenvironment and Their Impact on Cardiovascular Disease. Circ. Res. 2016, 118, 1786-1807. [CrossRef] [PubMed]

9. Galic, S.; Oakhill, J.S.; Steinberg, G.R. Adipose tissue as an endocrine organ. Mol. Cell. Endocrinol. 2010, 316, 129-139. [CrossRef] [PubMed]

10. Littlejohn, N.K.; Grobe, J.L. Opposing tissue-specific roles of angiotensin in the pathogenesis of obesity, and implications for obesity-related hypertension. Am. J. Physiol. Regul. Integr. Comp. Physiol. 2015, 309, R1463-R1473. [CrossRef] [PubMed]

11. Yvan-Charvet, L.; Quignard-Boulangé, A. Role of adipose tissue renin-angiotensin system in metabolic and inflammatory diseases associated with obesity. Kidney Int. 2011, 79, 162-168. [CrossRef] [PubMed]

12. Kalupahana, N.S.; Moustaid-Moussa, N. The adipose tissue renin-angiotensin system and metabolic disorders: A review of molecular mechanisms. Crit. Rev. Biochem. Mol. Biol. 2012, 47, 379-390. [CrossRef] [PubMed]

13. Favre, G.A.; Esnault, V.L.M.; Van Obberghen, E. Modulation of glucose metabolism by the renin-angiotensin-aldosterone system. Am. J. Physiol. Endocrinol. Metab. 2015, 308, E435-E449. [CrossRef] [PubMed]

14. Tamura, K.; Tanaka, Y.; Tsurumi, Y.; Azuma, K.; Shigenaga, A.; Wakui, H.; Masuda, S.; Matsuda, M. The role of angiotensin AT1 receptor-associated protein in renin-angiotensin system regulation and function. Curr. Hypertens. Rep. 2007, 9, 121-127. [CrossRef] [PubMed]

15. Tamura, K.; Wakui, H.; Maeda, A.; Dejima, T.; Ohsawa, M.; Azushima, K.; Kanaoka, T.; Haku, S.; Uneda, K.; Masuda, S.; et al. The physiology and pathophysiology of a novel angiotensin receptor-binding protein ATRAP/Agtrap. Curr. Pharm. Des. 2013, 19, 3043-3048. [CrossRef] [PubMed]

16. Maeda, A.; Tamura, K.; Wakui, H.; Dejima, T.; Ohsawa, M.; Azushima, K.; Kanaoka, T.; Uneda, K.; Matsuda, M.; Yamashita, A.; et al. Angiotensin receptor-binding protein ATRAP/Agtrap inhibits metabolic dysfunction with visceral obesity. J. Am. Heart Assoc. 2013, 2, e000312. [CrossRef] [PubMed]

17. Tamura, K.; Wakui, H.; Azushima, K.; Uneda, K.; Haku, S.; Kobayashi, R.; Ohki, K.; Haruhara, K.; Kinguchi, S.; Matsuda, M.; et al. Angiotensin II Type 1 Receptor Binding Molecule ATRAP as a Possible Modulator of Renal Sodium Handling and Blood Pressure in Pathophysiology. Curr. Med. Chem. 2015, 22, 3210-3216. [CrossRef] [PubMed]

18. Eguchi, J.; Wang, X.; Yu, S.; Kershaw, E.E.; Chiu, P.C.; Dushay, J.; Estall, J.L.; Klein, U.; Maratos-Flier, E.; Rosen, E.D. Transcriptional control of adipose lipid handling by IRF4. Cell Metab. 2011, 13, $249-259$. [CrossRef] [PubMed]

19. Urs, S.; Harrington, A.; Liaw, L.; Small, D. Selective expression of an aP2/Fatty Acid Binding Protein 4-Cre transgene in non-adipogenic tissues during embryonic development. Transgenic Res. 2006, 15, 647-653. [CrossRef] [PubMed]

20. Ferrell, R.E.; Kimak, M.A.; Lawrence, E.C.; Finegold, D.N. Candidate gene analysis in primary lymphedema. Lymphat. Res. Biol. 2008, 6, 69-76. [CrossRef] [PubMed]

21. Jeffery, E.; Berry, R.; Church, C.D.; Yu, S.; Shook, B.A.; Horsley, V.; Rosen, E.D.; Rodeheffer, M.S. Characterization of Cre recombinase models for the study of adipose tissue. Adipocyte 2014, 3, $206-211$. [CrossRef] [PubMed]

22. Lee, K.Y.; Russell, S.J.; Ussar, S.; Boucher, J.; Vernochet, C.; Mori, M.A.; Smyth, G.; Rourk, M.; Cederquist, C.; Rosen, E.D.; et al. Lessons on conditional gene targeting in mouse adipose tissue. Diabetes 2013, 62, 864-874. [CrossRef] [PubMed] 
23. Kang, S.; Kong, X.; Rosen, E.D. Adipocyte-specific transgenic and knockout models. Methods Enzymol. 2014, 537, 1-16. [PubMed]

24. Vooijs, M.; Jonkers, J.; Berns, A. A highly efficient ligand-regulated Cre recombinase mouse line shows that LoxP recombination is position dependent. EMBO Rep. 2001, 2, 292-297. [CrossRef] [PubMed]

25. Feil, S.; Valtcheva, N.; Feil, R. Inducible Cre mice. Methods Mol Biol. 2009, 530, 343-363. [PubMed]

26. Shigenaga, A.; Tamura, K.; Wakui, H.; Masuda, S.; Azuma, K.; Tsurumi-Ikeya, Y.; Ozawa, M.; Mogi, M.; Matsuda, M.; Uchino, K.; et al. Effect of olmesartan on tissue expression balance between angiotensin II receptor and its inhibitory binding molecule. Hypertension 2008, 52, 672-678. [CrossRef] [PubMed]

27. Dejima, T.; Tamura, K.; Wakui, H.; Maeda, A.; Ohsawa, M.; Kanaoka, T.; Haku, S.; Kengo, A.; Masuda, S.; Shigenaga, A.; et al. Prepubertal angiotensin blockade exerts long-term therapeutic effect through sustained ATRAP activation in salt-sensitive hypertensive rats. J. Hypertens. 2011, 29, 1919-1929. [CrossRef] [PubMed]

28. Wakui, H.; Tamura, K.; Matsuda, M.; Bai, Y.; Dejima, T.; Shigenaga, A.; Masuda, S.; Azuma, K.; Maeda, A.; Hirose, T.; et al. Intrarenal suppression of angiotensin II type 1 receptor binding molecule in angiotensin II-infused mice. Am. J. Physiol. Renal. Physiol. 2010, 299, F991-F1003. [CrossRef] [PubMed]

29. Wakui, H.; Tamura, K.; Tanaka, Y.; Matsuda, M.; Bai, Y.; Dejima, T.; Masuda, S.; Shigenaga, A.; Maeda, A.; Mogi, M.; et al. Cardiac-specific activation of angiotensin II type 1 receptor-associated protein completely suppresses cardiac hypertrophy in chronic angiotensin II-infused mice. Hypertension 2010, 55, 1157-1164. [CrossRef] [PubMed]

30. Matsuda, M.; Tamura, K.; Wakui, H.; Maeda, A.; Ohsawa, M.; Kanaoka, T.; Azushima, K.; Uneda, K.; Haku, S.; Tsurumi-Ikeya, Y.; et al. Upstream stimulatory factors 1 and 2 mediate the transcription of angiotensin II binding and inhibitory protein. J. Biol. Chem. 2013, 288, 19238-19249. [CrossRef] [PubMed]

31. Cannon, B.; Nedergaard, J. Brown adipose tissue: Function and physiological significance. Physiol. Rev. 2004, 84, 277-359. [CrossRef] [PubMed]

32. Wang, Z.V.; Deng, Y.; Wang, Q.A.; Sun, K.; Scherer, P.E. Identification and characterization of a promoter cassette conferring adipocyte-specific gene expression. Endocrinology 2010, 151, 2933-2939. [CrossRef] [PubMed]

33. Mullican, S.E.; Tomaru, T.; Gaddis, C.A.; Peed, L.C.; Sundaram, A.; Lazar, M.A. A novel adipose-specific gene deletion model demonstrates potential pitfalls of existing methods. Mol. Endocrinol. 2013, 27, 127-134. [CrossRef] [PubMed]

34. Azushima, K.; Ohki, K.; Wakui, H.; Uneda, K.; Haku, S.; Kobayashi, R.; Haruhara, K.; Kinguchi, S.; Matsuda, M.; Maeda, A.; et al. Adipocyte-Specific Enhanchment of Angiotensin II Type 1 Receptor-Associated Protein Ameliorates Diet-Induced Visceral Obesity and Insulin Resistance. J. Am. Heart Assoc. 2017, 6, e004488. [CrossRef] [PubMed]

35. Mishina, M.; Sakimura, K. Conditional gene targeting on the pure C57BL/ 6 genetic background. Neurosci. Res. 2007, 58, 105-112. [CrossRef] [PubMed]

36. Azushima, K.; Tamura, K.; Wakui, H.; Maeda, A.; Ohsawa, M.; Uneda, K.; Kobayashi, R.; Kanaoka, T.; Dejima, T.; Fujikawa, T.; et al. Bofu-tsu-shosan, an oriental herbal medicine, exerts a combinatorial favorable metabolic modulation including antihypertensive effect on a mouse model of human metabolic disorders with visceral obesity. PLoS ONE 2013, 8, e75560. [CrossRef] [PubMed]

(C) 2017 by the authors. Licensee MDPI, Basel, Switzerland. This article is an open access article distributed under the terms and conditions of the Creative Commons Attribution (CC BY) license (http:/ / creativecommons.org/licenses/by/4.0/). 